\title{
Upregulation of microRNA-1 inhibits proliferation and metastasis of breast cancer
}

\author{
JING PENG, CHENWEI YUAN, ZIPING WU, YAN WANG, WENJIN YIN, \\ YANPING LIN, LIHENG ZHOU and JINSONG LU
}

Department of Breast Surgery, Renji Hospital, School of Medicine, Shanghai Jiaotong University, Shanghai 200127, P.R. China

Received July 2, 2019; Accepted March 31, 2020

DOI: $10.3892 / \mathrm{mmr} .2020 .11111$

\begin{abstract}
Recent studies have shown that microRNAs (miRs) play a key role in the regulation of cancer development. In the present study, reverse transcription-quantitative PCR was used to detect the expression of miR-1 in breast cancer and adjacent tissues, and survival analysis was performed to compare the low-expression groups with the Kaplan-Meier method. Overexpression of miR-1 was used to observe the effects on the proliferation, migration and invasion of breast cancer cells in vitro and in vivo. Moreover, Bcl-2 expression was measured by western blotting and luciferase assays after the overexpression of miR-1. The present study reported that miR-1 is expressed at low levels in breast cancer and that cell proliferation, migration and invasion are inhibited in miR-1-overexpressing cells. Enhanced miR-1 expression can also increase cell apoptosis. The present study also demonstrated that Bcl-2 is a potential target of miR-1. In vivo studies indicate that overexpression of miR-1 decreases tumor volume and weight in nude mice. The data from the present study demonstrated for the first time that overexpression of miR-1 increases the sensitivity of breast cancer cells to paclitaxel and cisplatin. The present study provided new evidence for the important role of miR-1 in the tumorigenesis and drug sensitivity of breast cancer.
\end{abstract}

\section{Introduction}

Breast cancer $(\mathrm{BC})$ is the most frequently diagnosed malignant tumor and the second leading cause of cancer-related mortality in women (1). Despite advances in early detection and treatment, $\sim 30 \%$ of $\mathrm{BC}$ patients develop tumor metastasis during treatment $(2,3)$. Due to the diversity of breast tumors, the discovery of effective treatments is challenging. Although

Correspondence to: Dr Jinsong Lu or Dr Liheng Zhou, Department of Breast Surgery, Renji Hospital, School of Medicine, Shanghai Jiaotong University, 160 Pujian Road, Shanghai 200127, P.R. China E-mail: lujjss@163.com

E-mail: kaneshiro_lily@hotmail.com

Key words: breast cancer, microRNA-1, Bcl-2, proliferation, metastasis currently available chemotherapies have led to an increase in overall survival, numerous breast tumors may acquire resistance following the initial response $(4,5)$. It is therefore important to identify and investigate new molecular targets that inhibit BC progression and metastasis by affecting gene pathways and restoring drug susceptibility.

A previous study indicated that non-coding RNA plays an important regulatory role in BC development and progression (6). MicroRNAs (miRNAs/miRs) belong to a class of evolutionarily conserved RNAs that influence gene expression at the post-transcriptional level (7). Experimental studies have shown that abnormal expression of miRNA is associated with tumorigenesis and cancer metastasis $(8,9)$.

miR-1 is abundantly expressed in muscle, where it inhibits the proliferation of progenitor cells and promotes myogenesis. It is expressed in the cytoplasm of carcinoma cells and had been shown to suppress tumor growth in numerous cancer types (10). For example, miR-1 is the lowest expressed miRNA in prostate tumors and is considered a candidate tumor suppressor and prognostic marker for prostate cancer (11).

Previous reports suggest that miR-1 may suppress tumor proliferation in $\mathrm{BC}(12,13)$. The aim of the present study was to determine a novel molecular network involved in $\mathrm{BC}$ development by investigating the functional role of miR-1 using in vitro and in vivo experiments.

\section{Materials and methods}

Patient samples. Breast cancer tissues and adjacent normal breast tissues were obtained from the Breast Surgery Department of the Hospital of Shanghai, Jiaotong University. A total number of 47 women aged from 30-75 years old with histologically confirmed invasive ER-positive subtype BC were included. Patients were recruited from 2015 September to 2017 August. Immunohistochemical staining of ER/progesterone receptor (PR) and fluorescent in situ hybridization of human epidermal growth factor receptor (HER) 2 after surgery was performed as a regular procedure by pathologists. There was no radiotherapy or chemotherapy prior to surgery. All BC patients provided written consent for the use of their specimens in the present study, which was approved by the independent ethics committee of Renji Hospital, School of Medicine, Shanghai Jiaotong University (China). Breast tissue samples were collected immediately following resection and then stored at $-80^{\circ} \mathrm{C}$ before RNA extraction. 
$R N A$ isolation and reverse transcription-quantitative $(R T-q)$ $P C R$. Total RNA from $1 \times 10^{6}$ cultured cells and tissue samples was isolated using TRIzol reagent (Invitrogen; Thermo Fisher Scientific, Inc.). The quality and concentration of RNA was detected with NanoDrop 2000 (Thermo Fisher Scientific, Inc.). A miRcute miRNA first-strand cDNA synthesis kit and a miRcute miRNA qPCR kit were used to detect the miRNA expression level according to the manufacturer's protocols (Tiangen Biotech Co., Ltd.). The primers used for U6 snRNA (CD201-0145) and miR-1 (CD201-0003) were also obtained from Tiangen Biotech Co., Ltd. The mRNA expression level was detected by RT-PCR using a Takara Reverse Transcriptase kit and a SYBR Green PCR kit according to the manufacturer's protocols (Takara Biotechnology Co., Ltd.). The following thermocycling conditions were used for the qPCR: Initial denaturation at $95^{\circ} \mathrm{C}$ for $30 \mathrm{sec}$; followed by 40 cycles of denaturation at $95^{\circ} \mathrm{C}$ for $5 \mathrm{sec}$, annealing at $60^{\circ} \mathrm{C}$ for $10 \mathrm{sec}$ and extension at $72^{\circ} \mathrm{C}$ for $30 \mathrm{sec}$. Each sample was tested in triplicate. Expression levels were quantified using the $2^{-\triangle \Delta C q}$ method (14) and normalized to the internal reference gene, U6 for miR-1 expression or GAPDH for other genes. The primer sequences were as follows: GAPDH forward, 5'-GAA GGTGAAGGTCGGAGTC-3' and reverse 5'-GAAGATGGT GATGGGATTTC-3'; and Bcl-2 forward, 5'-AGTCTGGGA ATCGATCTGGA-3' and reverse 5'-GCAACGATCCCATCA ATCTT-3'. The primers used for miR-1 and U6 were described in a previous report (15).

Cell culture. Human breast cancer cell lines (MCF-7 and ZR-7530) were cultured in DMEM (Gibco; Thermo Fisher Scientific, Inc.) supplemented with $10 \%$ fetal bovine serum (Gibco; Thermo Fisher Scientific, Inc.) and 1\% (v/v) penicillin/streptomycin. All cells were cultured in a humidified atmosphere of $5 \% \mathrm{CO}_{2}$ and $95 \%$ air at $37^{\circ} \mathrm{C}$. The cells were purchased from The Type Culture Collection of the Chinese Academy of Sciences.

Overexpression of miR-1 in cells. The $\mathrm{pLV}$-hsa-miR-1 plasmid and the negative control pLV-miRNA-vector were purchased from Shanghai GenePharma Co., Ltd. The viruses were packaged in 293T (Type Culture Collection of the Chinese Academy of Sciences) cells according to standard protocols and the virus particles were harvested $72 \mathrm{~h}$ later. The packaged lentiviruses were termed LV-miR-1, while the empty lentiviral vector $\mathrm{LV}$-ctrl was used as a control. Cells were infected with viral particles (MOI $=10$ for each) for $24 \mathrm{~h}$ and $5 \mu \mathrm{g} / \mathrm{ml}$ Polybrene, which was followed by selection with puromycin $(2 \mu \mathrm{g} / \mathrm{ml})$ for $\leq 7$ days. Polybrene and puromycin were purchased from Shanghai GenePharma Co., Ltd.

Cell proliferation assay. The Cell Counting Kit-8 method was used according to the manufacturer's protocol to determine cell proliferation (Dojindo Molecular Technologies, Inc.). MCF-7 and ZR-7530 cells transfected with either LV-miR-1 or LV-ctrl were seeded into 96-well plates at a density of $5 \times 10^{3}$ cells/well, and then $10 \mu \mathrm{l} \mathrm{CCK}-8$ solution was added to each well so that the final volume of culture medium was $200 \mu \mathrm{l}$. To perform the clonogenic assay, $5 \times 10^{3}$ cells were seeded in a $10 \mathrm{~cm}$ dish. Visible colonies were fixed in $4 \%$ formaldehyde at room temperature for $30 \mathrm{~min}$ and after 10 days, the colonies were stained with $0.1 \%$ crystal violet at room temperature for $30 \mathrm{~min}$. EdU incorporation assay was performed using EdU incorporation assay kit (Guangzhou RiboBio Co., Ltd.) according to the manufacturer's instructions.

Cell migration and invasion assays. Cell migration and invasion capacity were determined using a Transwell assay using Transwell permeable supports (Corning, Inc.). A total of $1 \times 10^{5}$ breast cancer cells/well were plated in the upper chambers of Transwell plates with serum-free DMEM medium, of which membranes were or were not precoated with Matrigel (BD Biosciences) for the invasion and migration assay, respectively. Modified Boyden chambers containing Matrigel were placed in a 24-well culture plate. Matrigel was precoated for $12 \mathrm{~h}$ at $37^{\circ} \mathrm{C}$. A total of $800 \mu \mathrm{l}$ DMEM medium supplemented with $10 \%$ FBS was plated in the lower chambers. After $24 \mathrm{~h}$ incubation in wells without Matrigel or $48 \mathrm{~h}$ with Matrigel, migration and invasion were assessed, respectively. Then, cells in the lower chambers were fixed in $4 \%$ paraformaldehyde at room temperature for $30 \mathrm{~min}$ and stained with a $0.5 \%$ crystal violet fixative solution for $30 \mathrm{~min}$ at room temperature, following which the cells were counted using an inverted fluorescent microscope (magnification, x200; Leica Microsystems, Inc.).

Apoptosis assay. Cells transfected with the LV-miR-1 or the negative control (NC) were collected and stained with Annexin-V-FITC and 7-AAD using an FITC Annexin V apoptosis detection kit (PE Annexin V Apoptosis Detection kit; BD Pharmingen; BD Biosciences) according to the manufacturer's protocol. Apoptosis was subsequently detected using a FACScan flow cytometer (BD Biosciences). Flow cytometry data was analyzed by BD FACSDiva software V6.1.3 (BD Biosciences). The cells were divided into dead cells, early apoptotic cells, apoptotic cells and viable cells and the percentages of apoptotic cells calculated. Cells considered viable were PE Annexin V- and 7-AAD-negative, early apoptotic cells were PE Annexin V-positive and 7-AAD-negative, and late apoptotic cells and dead cells were positive for both PE Annexin V and 7-AAD.

Western blotting. Breast cancer cells were harvested 3 days after transfection and were lysed in RIPA buffer (Beyotime Institute of Biotechnology). Total protein was quantified using a bicinchoninic acid assay kit. A total of $30 \mu \mathrm{g}$ protein/lane was separated by 8 or $12 \%$ SDS-PAGE followed by transfer of the proteins to a nitrocellulose filter membrane. After blocking in 5\% BSA (Shanghai Shenggong Biology Engineering Technology Service, Ltd.) at $25^{\circ} \mathrm{C}$ for $2 \mathrm{~h}$, the membranes were subjected to incubation with primary antibodies $(1: 1,000)$ overnight at $4^{\circ} \mathrm{C}$. Following the primary antibody incubation, membranes were incubated with horseradish peroxidase-conjugated goat anti-rabbit secondary antibodies (1:5,000; cat. no. 7074; Cell Signaling Technology, Inc.). $\beta$-actin served as the loading control. The protein immunoreactive bands were visualized by the ECL detection instrument (Thermo Fisher Scientific, Inc.) plus chemiluminescent substrate. Densitometry analysis was performed using ImageJ software (version 1.8.0; National Institutes of Health) with $\beta$-actin as the internal control. Detailed information on the antibodies used is given in Table SI. 
Dual luciferase reporter assay. The Bcl-2 3'UTR sequences to which miR-1 potentially bind were searched by TargetScan (http://www.targetscan.org). Then, the DNA fragments of the 3'UTR of Bcl-2 were cloned into the dual-luciferase expression vector, pmirGLO (Promega Corporation), which was termed $\mathrm{wt}-\mathrm{Bcl} 2$. The mutant vector was generated by mutating the miR-1 seed region binding site and this vector was termed mut-Bcl2. The miR-1 mimics, the miR-1 control, the firefly luciferase reporter plasmid and the Renilla luciferase vector (pRL-SV40, Promega Corporation) were co-transfected into BC cells using Lipofectamine ${ }^{\circledR} 2000$ (Invitrogen; Thermo Fisher Scientific, Inc.) and the luciferase activity was evaluated using a dual-luciferase reporter assay kit (Promega Corporation).

Analysis of the epigenetic silencing of miR-1. 5-Azacytidine (5-AzaC) and trichostatin A (TSA) were purchased from Sigma-Aldrich (Merck KGaA). Briefly, ZR7530 and MCF-7 cells were plated at a density of $1 \times 10^{6}$ cells per $10 \mathrm{~cm}$ and were then treated with 5 -AzaC $(5 \mu \mathrm{M})$ and/or TSA $(0.3 \mu \mathrm{M})$. Cells were cultured in this medium at $37^{\circ} \mathrm{C}$ for 2 days before they were harvested for RNA extraction.

Effect of miR-1 on paclitaxel and cis-platinum sensitivities. The MCF-7 cells transfected with either LV-miR-1 or LV-ctrl were seeded into 96 -well plates $\left(1 \times 10^{4}\right.$ cells/well). After $24 \mathrm{~h}$, the appropriate cytotoxic drug was added: $10 \mathrm{nM}$ paclitaxel or $0.2 \mu \mathrm{M}$ cisplatin (DDP). Drug sensitivities were measured using a CCK- 8 assay, as described above. DDP-resistant MDA-MB-231 cells were obtained from Shanghai Longhua Hospital. The $\mathrm{IC}_{50}$ of MDA-MB-231 and MDA-MB-231/DDP to DDP was 17.72 and $173.70 \mu \mathrm{g} / \mathrm{ml}$, respectively, and the fold-resistance of MDA-MB-231/DDP cells to DDP was 9.80 (16).

Animal studies. A total of 16 female BALB/C athymic nude mice (age, 6 weeks; weight, $23 \mathrm{~g}$; SLAC, Shanghai, China) were housed and manipulated according to the protocols approved by the Renji Hospital Medical Experimental Animal Care Commission. The nude mice were housed in pathogen-free environment with 12-h light/dark cycle, controlled humidity $(50 \%)$ and temperature $\left(28^{\circ} \mathrm{C}\right)$ and had free access to food and water. For the in vivo studies, $5 \times 10^{6} \mathrm{LV}$-miR-1 or LV-miR-ctrl cells were injected subcutaneously in the backs of nude mice. The length and width of the tumors was measured every week and tumor volumes were calculated using the following formula: Volume $\left(\mathrm{mm}^{3}\right)=$ length $(\mathrm{L} ; \mathrm{mm}) \mathrm{x}$ width $(\mathrm{W} ; \mathrm{mm})^{2} / 2$. Then, 4 weeks following injection, the mice were euthanized by cervical dislocation and the tumors removed and weighed. The mice were maintained under specific pathogen-free conditions and fed sterile chow. Mice were housed and manipulated in accordance with the principles and guidelines approved by the Renji Hospital Medical Experimental Animal Care Commission.

Analysis of The Cancer Genome Atlas (TCGA) dataset. A normalized mRNA and miRNA expression dataset for BC was downloaded from the TCGA (http://www.tcga.org) (17) and Spearman's correlation coefficient was calculated for the $\mathrm{BC}$ samples. The expression of miR-1 in tumor and normal tissues was analyzed using data from TCGA project. The box plot in Fig. 1A presenting the median and range was download from the ENCORI Pan-Cancer Analysis Platform (http://starbase.sysu.edu.cn/panCancer.php).

Statistical analysis. Data are presented as the mean \pm SEM from three independent experiments. Statistical calculations were performed with $\mathrm{R}$ program (version 3.4; Rstudio, Inc.). The differences between the means were tested by Student's t-test or one-way ANOVA followed by Tukey post hoc test. Spearman's correlation analyses were used to identify the correlation between miR-1 and Bcl-2. $\mathrm{P}<0.05$ was considered to indicate a statistically significant difference. StarBase3 database was used to analyze the expression of miR-1 in breast cancer tissues and healthy tissues (http://starbase.sysu. edu.cn/). The Kaplan-Meier analysis of patient survival data in METABRIC and the Dataset GSE19783 were performed on Kaplan Meier-plotter (https://kmplot.com/analysis/).

\section{Results}

miR-1 expression is downregulated in BC and the low expression of miR-1 is correlated with poor survival. To determine whether miR-1 was involved in the tumorigenesis of BC, the expression of miR-1 was analyzed using StarBase3 database and the data showed that miR-1 was expressed at significantly low levels in BC samples compared with normal samples $(\mathrm{P}<0.0001$; Fig. 1A). Patient survival was analyzed according to the different patient groups and it was found that low miR-1 expression was correlated with poor overall survival only in luminal-type (ER-positive) patients, but not in human epidermal growth factor receptor 2-positive or triple-negative patients (Fig. S1). miR-1 expression was compared in 47 pairs of ER-positive BC tissues and normal breast tissues using the patient samples described above. The data demonstrated that miR-1 was expressed at low levels in $\mathrm{BC}$ tissues compared with normal breast tissues $(\mathrm{P}<0.05$; Fig. 1B), which indicated that miR-1 was a potential tumor suppressor in BC. A Kaplan-Meier analysis of patient survival data in METABRIC (Fig. 1C) and the Dataset GSE19783 (Fig. 1D) revealed that low miR-1 expression was correlated with poor overall survival. In hepatocellular carcinoma and prostate cancer, it has been reported that low expression of miR-1 is mediated by methylation $(18,19)$. To investigate whether miR-1 is epigenetically silenced in BC, MCF-7 cells were treated with either 5-AzaC or TSA. 5-AzaC is a well-known DNA hypomethylating agent and TSA is a histone deacetylase inhibitor. It was observed that miR-1 expression was activated following treatment with 5-AzaC and TSA $(\mathrm{P}<0.01$; Fig. 1E), which indicates that miR-1 may be epigenetically silenced in BC cells and may be why miR-1 is downregulated in $\mathrm{BC}$. This experiment demonstrated that miR-1 is expressed at low levels in breast cancer tissues and that a low level of miR-1 is correlated with poor survival.

Upregulation of miR-1 inhibits $B C$ cell proliferation. To investigate the role of miR-1 in cancer cell growth, $\mathrm{BC}$ cells (ZR-7530, MCF-7) were transfected with the LV-miR-1 and the expression of miR-1 was significantly increased (Fig. 2A). A CCK-8 assay demonstrated that overexpression of miR-1 significantly inhibited the growth capacity of BC cells 
A

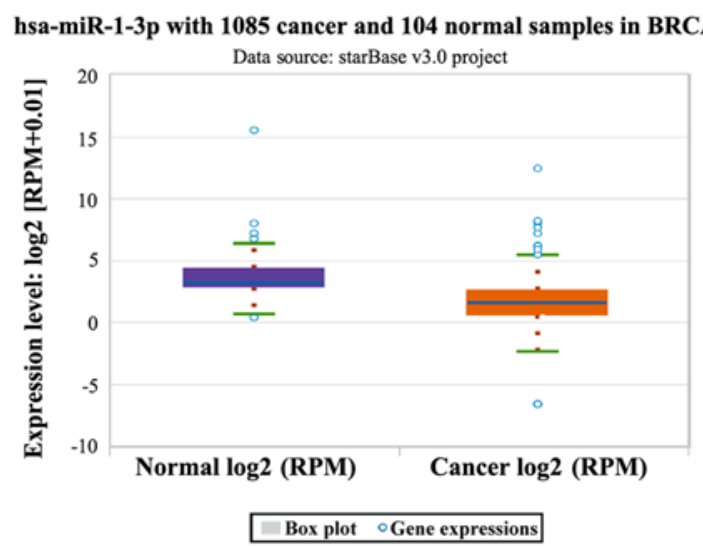

C

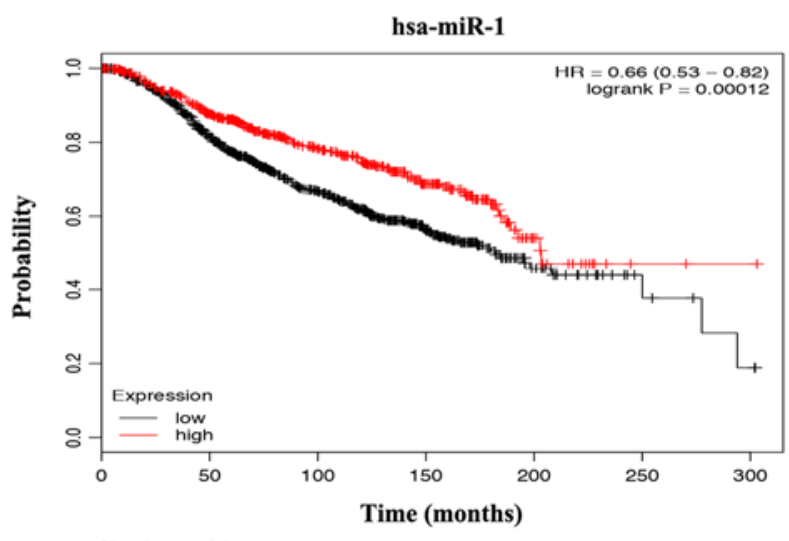

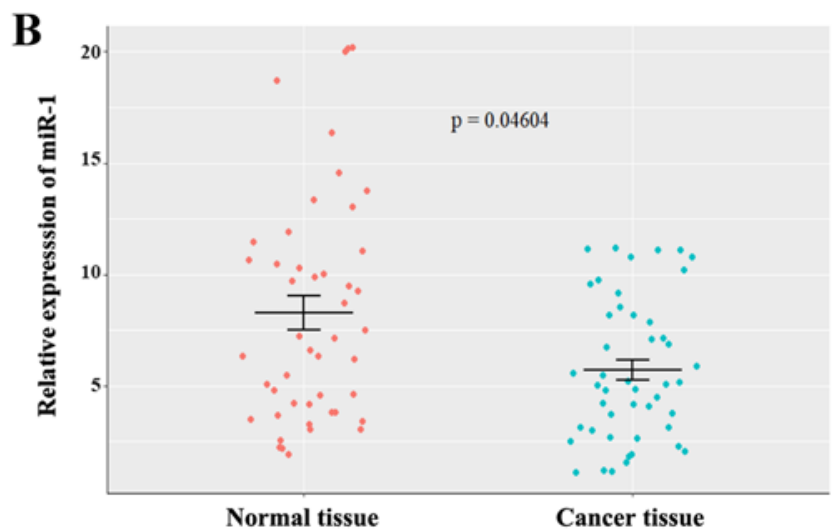

D

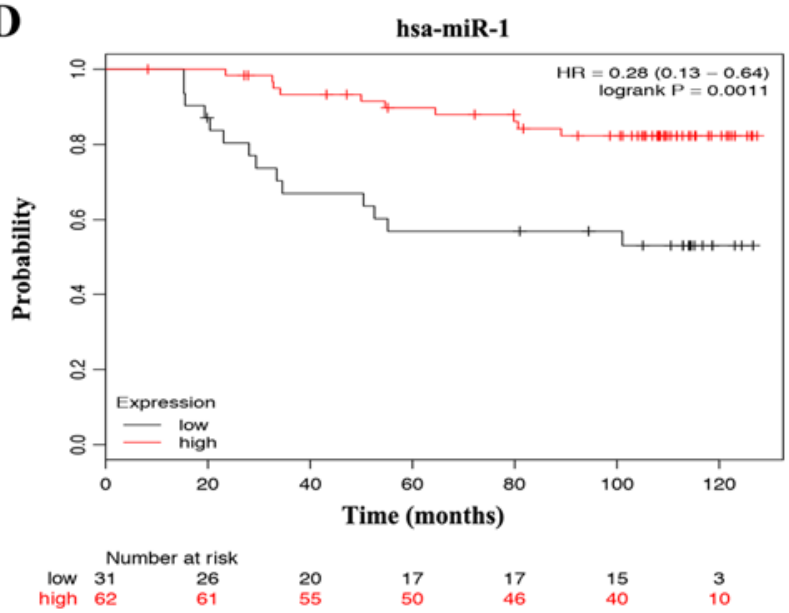

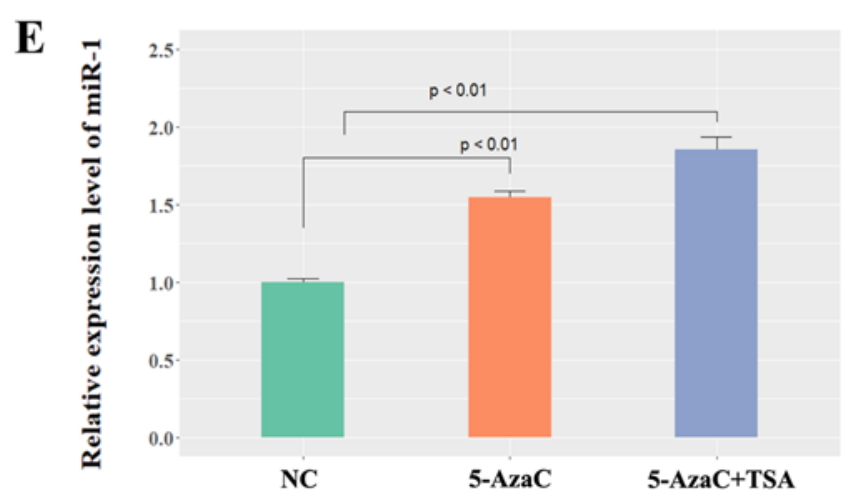

Figure 1. Expression level of miR-1 in BC. (A) miR-1 was expressed at low levels in BC tissues analyzed by the StarBase3 database. (B) miR-1 was expressed at low levels in $\mathrm{BC}$ tissues compared with normal breast tissues $(\mathrm{n}=47, \mathrm{P}=0.04604)$. (C) A high level of miR-1 was correlated with a good overall survival in $\mathrm{BC}$ patients according to data in METABRIC, $\mathrm{P}=0.00012$. (D) A low level of miR-1 was correlated with poor overall survival in $\mathrm{BC}$ patients according to Dataset GSE19783, $\mathrm{P}=0.0011$. (E) The miR-1 level was increased in MCF-7 human BC cells following 5-AzaC and TSA treatment ( $\mathrm{n}=3$, $\mathrm{P}<0.01)$. miR, microRNA; BC, breast cancer; 5-AzaC, 5-Azacytidine; TSA, trichostatin A; RPM, reads per million.

(Fig. 2B). Similarly, a clonogenic survival assay of BC cells demonstrated that upregulation of miR-1 significantly inhibited BC cell colony formation efficiency (Fig. 2C). A EdU proliferation assay also revealed that the capacity of $\mathrm{BC}$ cell proliferation was decreased in the LV-miR-1 group (Fig. 2D). Taken together, the data showed that enhanced miR-1 expression inhibits the proliferation of $\mathrm{BC}$ cells.

Upregulation of miR-1 inhibits cell migration and invasiveness of $B C$. Transwell migration and invasion assays were used to evaluate the effect of miR-1 on BC cell metastasis. As shown in the figures, migration (Fig. 3A) and invasion (Fig. 3B) were both significantly decreased in miR-1-transfected cells compared with the negative control. These results indicated that overexpression of miR-1 inhibits BC cell migration and invasion potential.

Upregulation of miR-1 can promote BC cell apoptosis. The flow cytometric analysis demonstrated that upregulation of miR-1 increased the rate of apoptosis in MCF-7 cells compared with the control (Fig. 4A). In addition, the expression levels of Bax, Bad, cleaved poly ADP ribose 


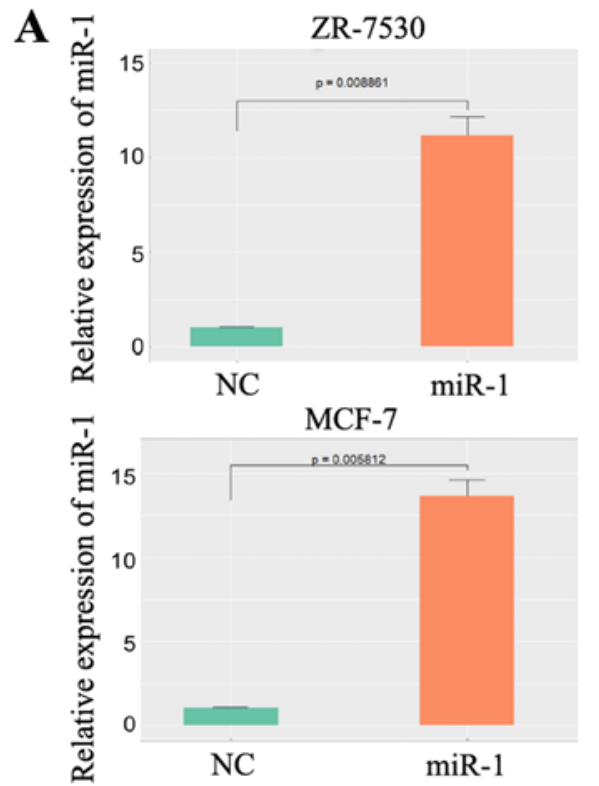

B
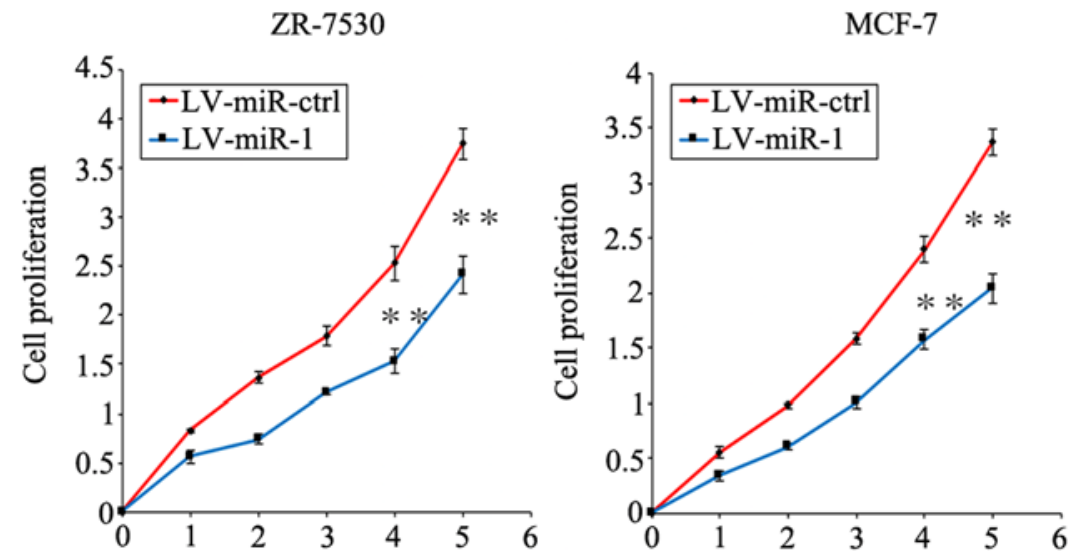

C

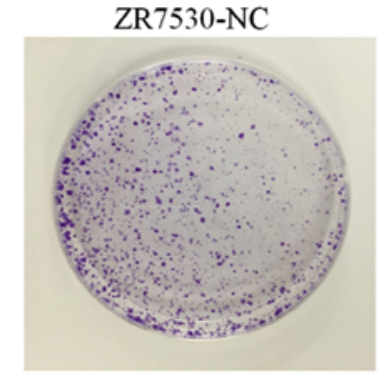

MCF7-NC

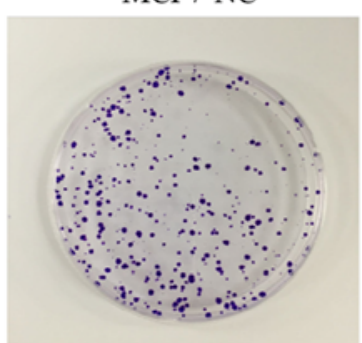

D

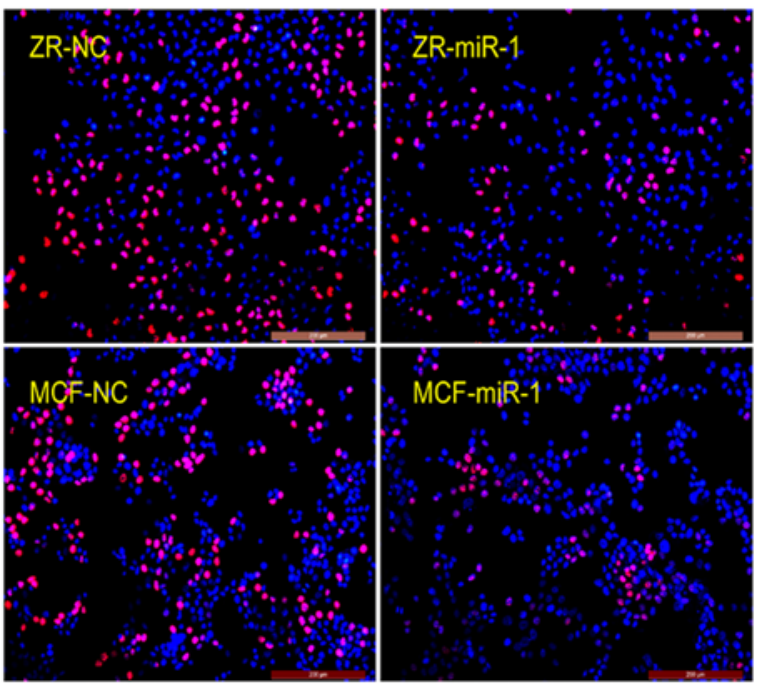

ZR7530-miR-1

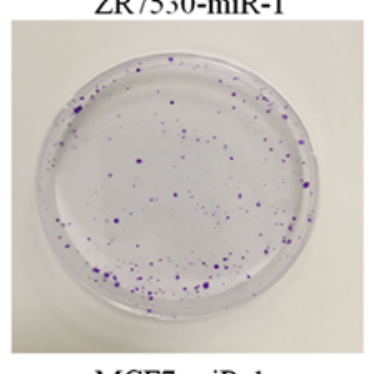

MCF7-miR-1

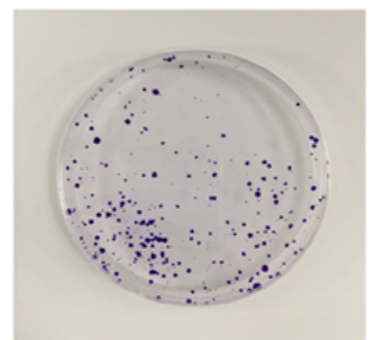

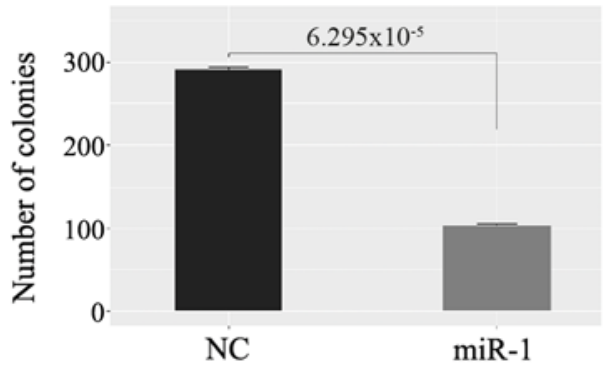
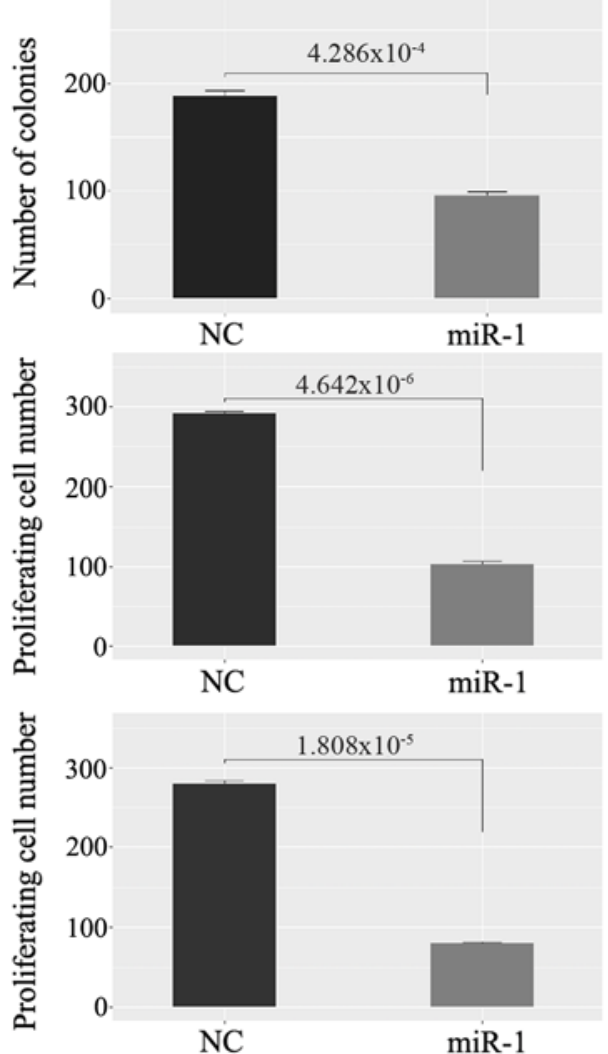

Figure 2. miR-1 inhibits BC cell growth. (A) Validation of miR-1 overexpression in BC cells ( $n=3, P<0.01)$. (B) A high level of miR-1 inhibited BC cell proliferation, as shown by CCK-8 assay (1-5: 12, 24, 48, 72 and $96 \mathrm{~h}), \mathrm{n}=6,{ }^{* *} \mathrm{P}<0.01$. (C) A high level of miR-1 inhibited $\mathrm{BC}$ cell clone formation, $\mathrm{n}=3, \mathrm{P}<0.01$. (D) A high level of miR-1 inhibited BC cell proliferation, as demonstrated by EdU essay, $\mathrm{n}=3, \mathrm{P}<0.01$. miR, microRNA; $\mathrm{BC}$, breast cancer; $\mathrm{NC}$, normal control; ctrl, control; LV, lentiviral. 
A
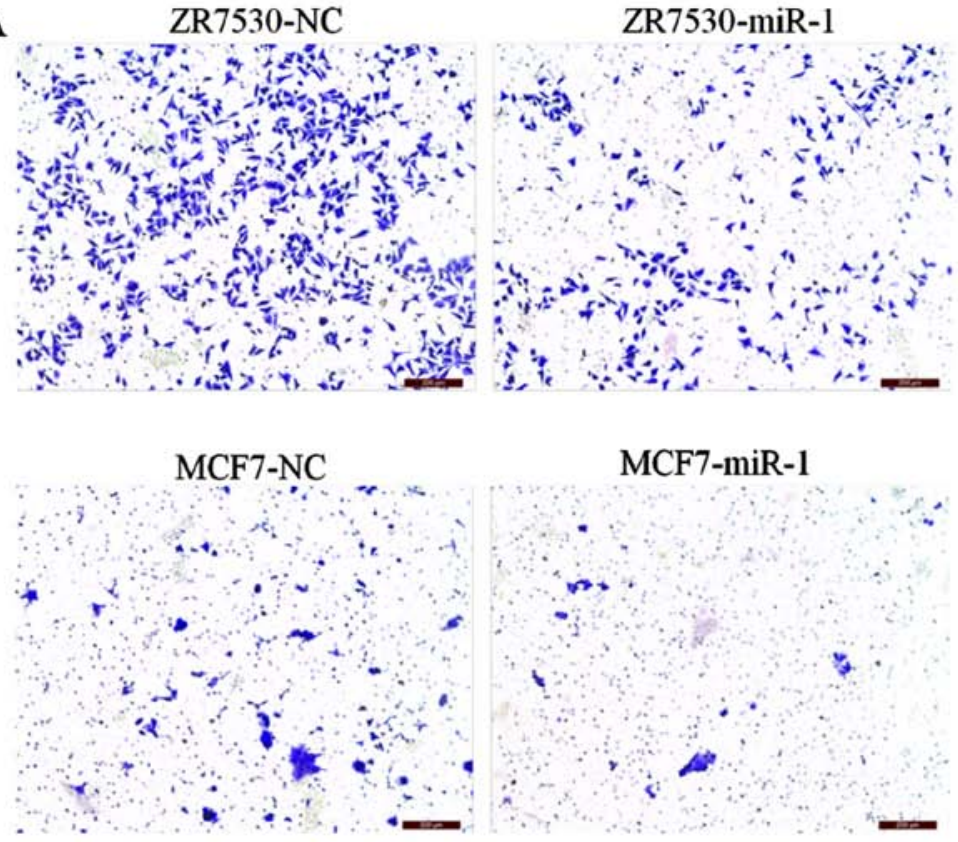

B
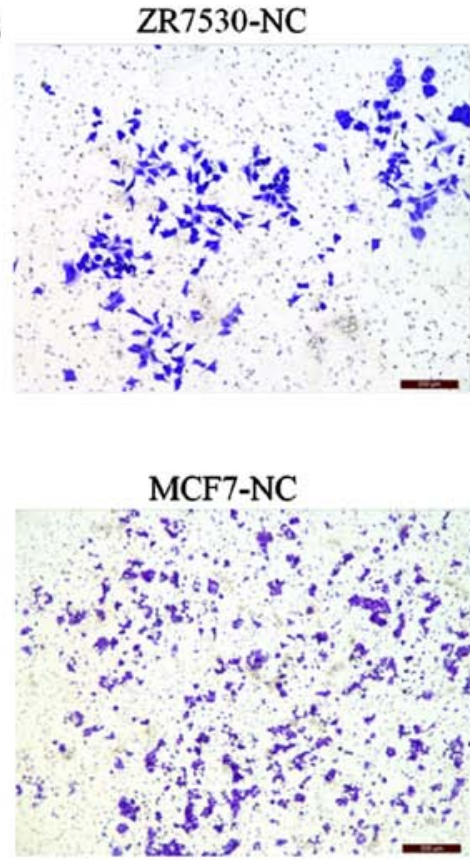

MCF7-miR-1

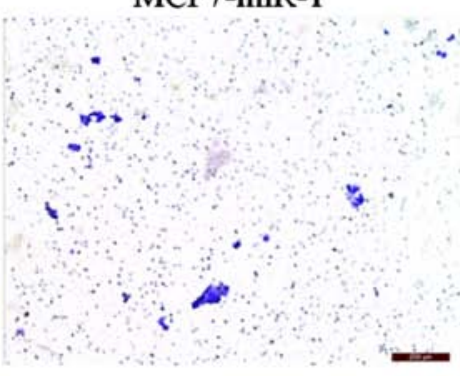

ZR7530-miR-1
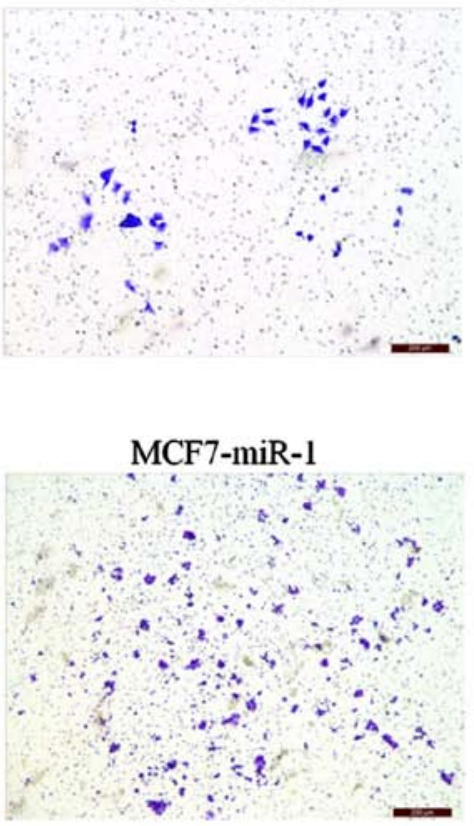
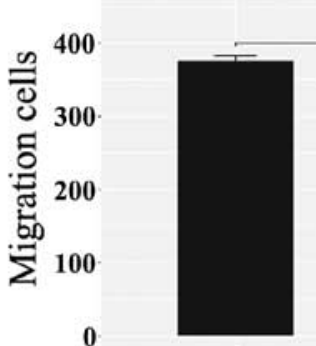

NC $9.766 \times 10^{-3}$

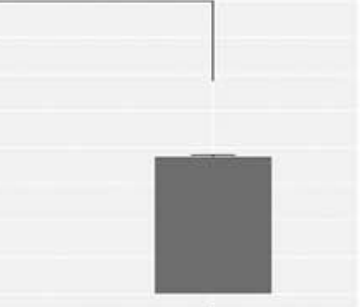

miR-1

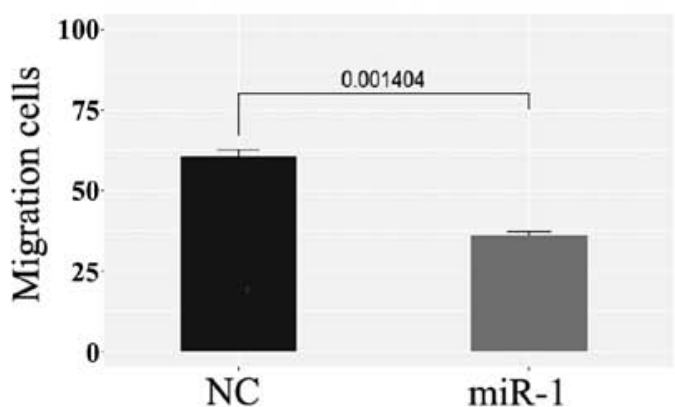

$2.809 \times 10^{-5}$
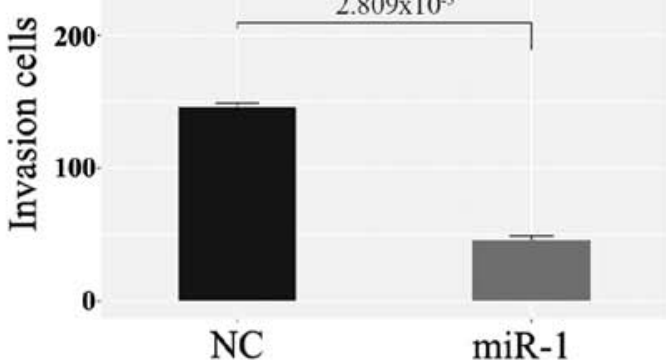

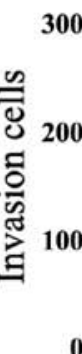

$1.143 \times 10^{-4}$

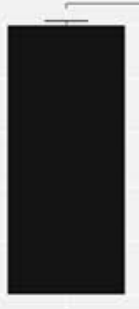

NC
miR-1

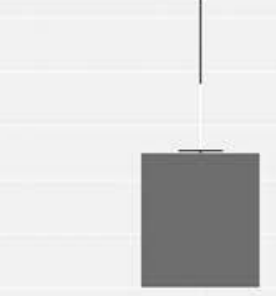

miR-1

Figure 3. Overexpression of miR-1 inhibits cell migration and invasion. (A) A high level of miR-1 inhibits the migration ability of $\mathrm{BC}$ cells, $\mathrm{n}=3$, $\mathrm{P}<0.01$ ). (B) A high level of miR-1 inhibits the invasion ability of BC cells, $\mathrm{n}=3, \mathrm{P}<0.01$, (scale bar=200 $\mu \mathrm{m}$ ). miR, microRNA; NC, normal control.

polymerase (PARP), and cleaved caspase-3, which are well-defined protein markers of apoptosis, were increased in miR-1-overexpressing cells (Fig. 4B). The expression levels of proliferation markers, such as p-AKT, p-ERK1/2, myeloid cell leukemia 1 (Mcl-1) and anti-binding immunoglobulin protein (BIP), were decreased in miR-1-overexpressing cells (Fig. 4C). Genes that regulate the cell cycle and DNA damage were also examined (Fig. S2A). However, for cyclin dependent kinase (CDK)4, CDK6 and BRCA2, no significant difference was observed between the $\mathrm{BC}$ cells that stably expressed miR-1 and the negative control cells. However, increased expression of p21 was observed in miR-1-overexpressing BC cells. Furthermore, the cell adhesion proteins E-cadherin and claudin-1 were upregulated, while the epithelial-mesenchymal transition (EMT)-related protein zinc finger E-box binding homeobox (ZEB)1 was downregulated in miR-1-overexpressing cells (Fig. 4D). The above results demonstrated that miR-1 may inhibit BC progression and metastasis by promoting the apoptosis of BC cells and by inhibiting cell proliferation and EMT. 
A

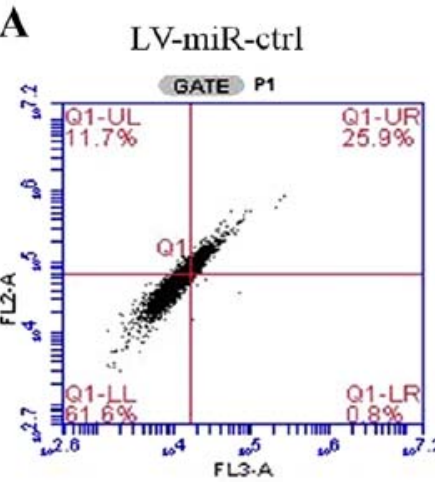

B

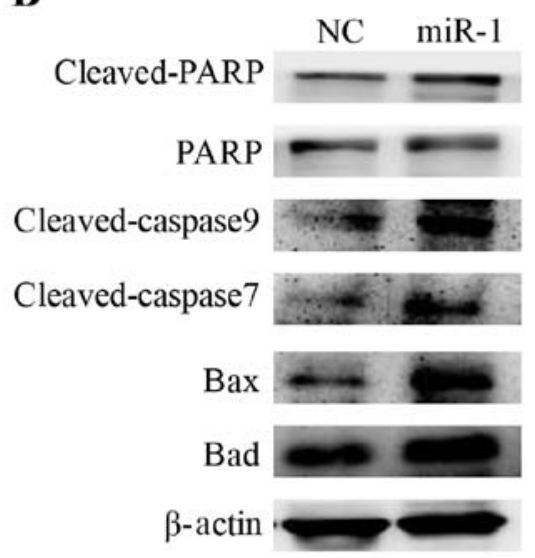

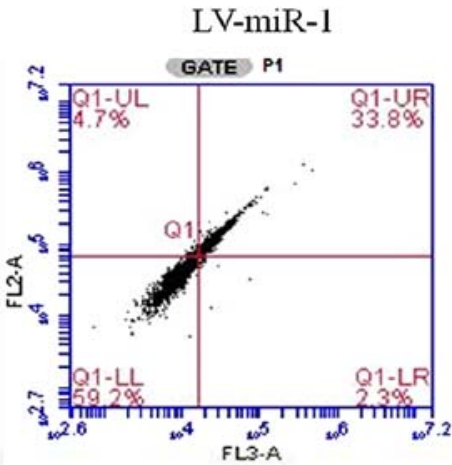

C

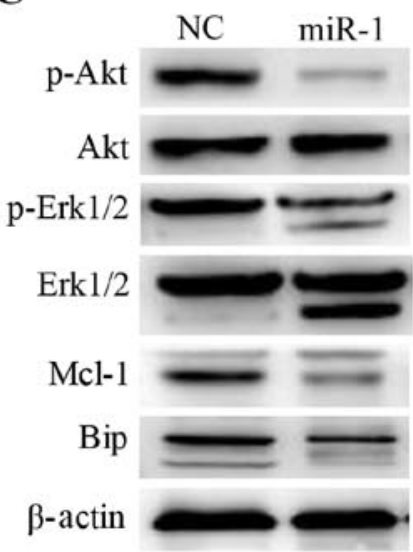

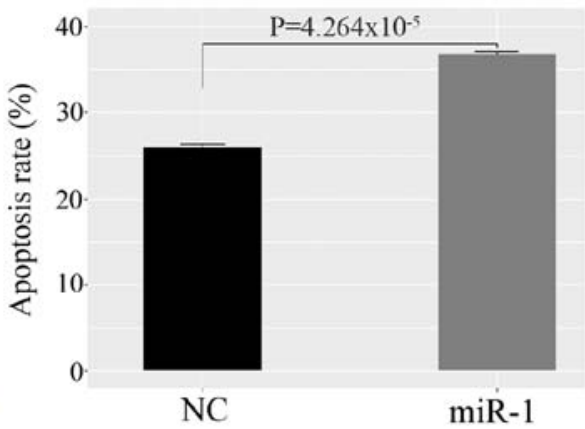

D

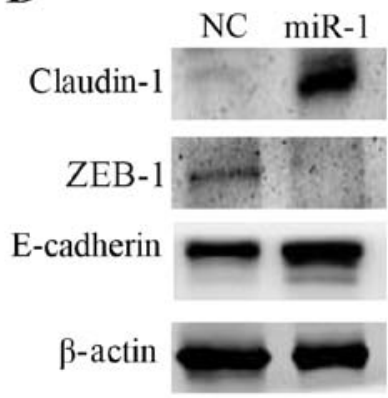

Figure 4. Upregulation of miR-1 promotes MCF-7 cell apoptosis. (A) miR-1 promotes apoptosis of MCF7 cells, as demonstrated by fluorescence activated cell sorting, $n=3, P<0.01$. (B) Proteins that promote apoptosis were upregulated in miR-1-overexpressing cells. (C) Proteins that inhibit apoptosis and induce proliferation were decreased in miR-1- overexpressing cells. (D) The cell adhesion protein claudin-1 was upregulated and the EMT-related proteins ZEB1 and E-cadherin were upregulated in miR-1-overexpressing cells. miR, microRNA; ctrl, control; NC, normal control; PARP, poly ADP ribose polymerase; Mcl-1, myeloid cell leukemia 1; Bip, binding immunoglobulin protein; EMT, epithelial-mesenchymal transition; ZEB1, zinc finger E-box binding homeobox 1.; LV, lentiviral.

Bcl-2 is a target of miR-1. The TargetScan search showed that the 3'UTR of the Bcl-2 gene contains miR-1 binding sites (Fig. 5A). Bcl-2 expression was analyzed in patient samples and Bcl-2 was highly expressed in BC tissues in contrast to normal breast tissues (Fig. S2B). Then, whether miR-1 can regulate the expression level of Bcl-2 was investigated and it was found that miR-1 downregulated Bcl-2 expression at the mRNA and protein levels in MCF-7 (Fig. 5B and C) and ZR-7530 cells (Fig. S2C and D). The wild-type and mutant Bcl-2 3'UTR were subcloned downstream of the luciferase gene and named wt-Bcl 2 and mut-Bcl2, respectively and were then transfected together with miR-1-3p mimics. It was observed that the luciferase activities of the wt-Bcl 2 vector was reduced following treatment with miR-1 mimics. In addition, luciferase activity in cells transfected with the mut-Bcl 2 and miR-1 mimic was almost comparable with that of the control cells (Fig. 5D). In addition, it was found that the expression level of miR-1 and Bcl-2 in BC tissues were negatively correlated according to data downloaded from the TCGA database (Fig. 5E), which also demonstrated that Bcl-2 may be a target of miR-1. Bcl-2 in MCF-7 cells were also modulated in the presence or absence of miR-1 mimics and then migration and invasion evaluated, as shown in Fig. S3A and B. The number of migrating and invading cells returned to levels similar to that of the $\mathrm{NC}$ group following ectopic Bcl-2 expression in miR-1-overexpressing cells. This finding demonstrated that overexpression of miR-1 inhibited cell migration and invasion, which is reversed by Bcl-2 overexpression. These data also showed that miR-1 can bind directly to $\mathrm{Bcl}-2$ through their respective miRNA recognition sites. Thus, it was demonstrated that Bcl-2 is a target gene of miR-1.

In vivo tumor growth is suppressed by upregulation of $m i R-1$. To explore the role of miR-1 in tumor growth in vivo, BC cells with a high level of miR-1 or the negative control cells were injected subcutaneously into nude mice. After 4 to 5 weeks, the mice were euthanized and intact tumors were removed (Fig. 6A). The tumor volumes and weight were measured and the results showed that the average tumor volumes were decreased in the miR-1 group compared with the negative control group (Fig. 6B). The tumor weight was also significantly decreased in the miR-1-overexpressing group (Fig. 6C). These results indicated that upregulation of miR-1 can suppress the growth of BC cells in vivo.

Upregulation of miR-1 enhances drug sensitivity in BC cells. It has been reported that overexpression of Bcl-2 and its close relatives is a major component of chemo-resistance (20), and since it was observed that miR-1 could downregulate Bcl-2, it was hypothesized that miR-1 may influence the sensitivity of 
A

\begin{tabular}{|c|c|}
\hline $\begin{array}{l}\text { Position 4048-4054 of BCL2 3' UTR } \\
\text { hsa-miR-1-3p }\end{array}$ & $\begin{array}{c}5^{\prime} \ldots \text { AUUUUUAAAUGUAAAACAUUCCC } \ldots \\
\quad \ldots \text { IIIIIIII } \\
3^{\prime} \quad \text { UAUGUAUGAAGAAAUGUAAGGU }\end{array}$ \\
\hline MUT BCL2 &.. AUUUUUAAAUGUAAAUGUAAGGC... \\
\hline
\end{tabular}

B

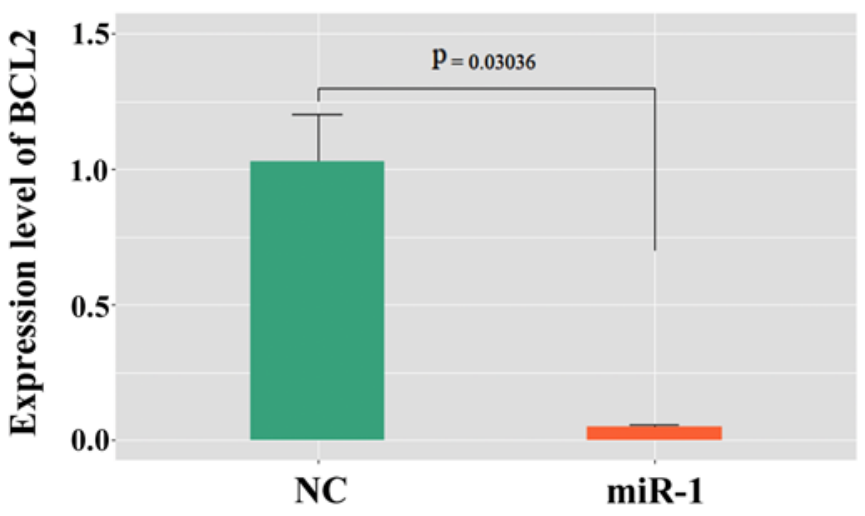

C
D

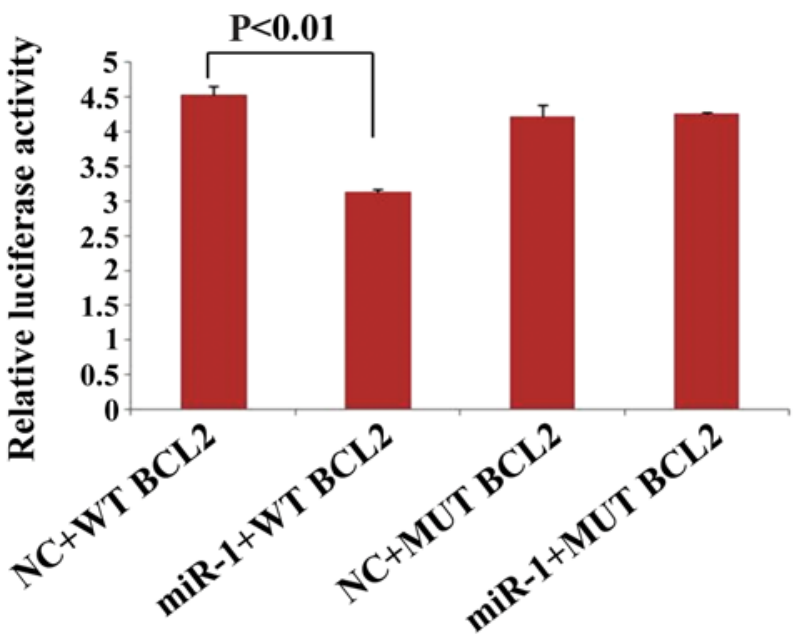

E

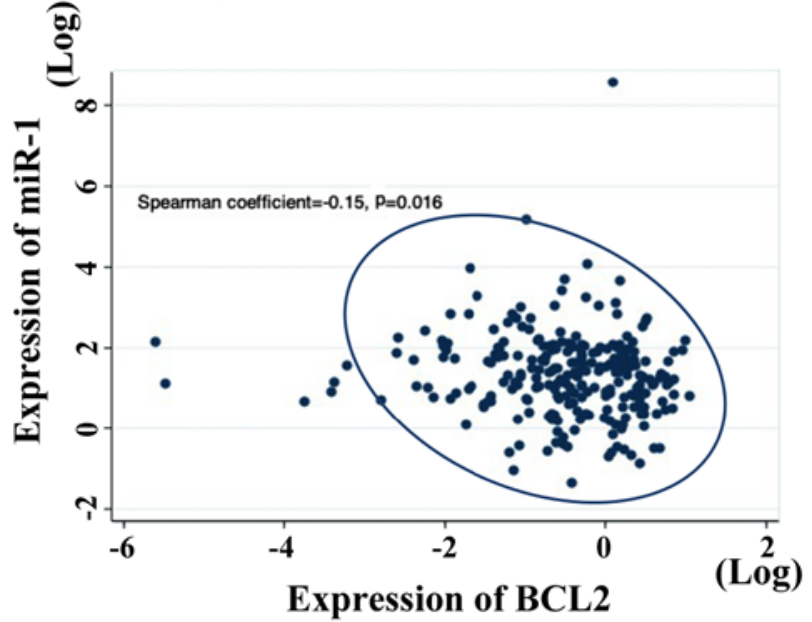

Figure 5. Bcl-2 is a direct target of miR-1. (A) The Bcl-2 5'UTR contains binding sites for miR-1 and the mutated sequence of the Bcl-2 3'UTR. (B) Bcl2 mRNA was decreased in miR-1- overexpressing MCF-7 cells, $n=3, P<0.01$. (C) Bcl2 protein was also decreased in miR-1-overexpressing MCF-7 cells. (D) Luciferase reporter assays in MCF7 cells showed that miR-1 can directly bind to the 3 'UTR of WT Bcl2 and decreased the luciferase activity, $\mathrm{n}=3$, $\mathrm{P}<0.01$. (E) The expression levels of miR-1 and Bcl-2 in BC tissues were negatively correlated according to data downloaded from the TCGA, $\mathrm{P}=0.016$. miR, microRNA; BC, breast cancer; NC, normal control; MUT, mutant; WT, wild type.

BC cells to drugs. Thus, cell viability was observed following treatment with paclitaxel or DDP. The results showed that overexpression of miR-1 can enhance the sensitivity of $\mathrm{BC}$ cells to paclitaxel and DDP because cell proliferation was decreased in the miR-1-overexpressing group compared with the control group (Fig. 7A and B). The expression level of miR-1 in DDP-resistant BC cells was also tested and the results demonstrated that the expression of miR-1 is significantly decreased in resistant $\mathrm{BC}$ cells compared with parental $\mathrm{BC}$ cells $(\mathrm{P}=0.046$; Fig. $7 \mathrm{C})$. Taken together, the data from the present study indicated that overexpression of miR-1 could enhance drug sensitivity in BC cells.

\section{Discussion}

miR-1 has been shown to be downregulated in some cancer types, where it inhibits tumor growth $(21,22)$. However, the specific role and mechanism of miR-1 in BC requires further elucidation. It was revealed that miR-1 was expressed at a low level in BC tissues and that overexpression of miR-1 inhibited $\mathrm{BC}$ cell proliferation and migration. For the first time, to the best of the authors' knowledge the present study illustrated the interaction between miR-1 and Bcl-2 in BC cells and showed that miR-1 promoted cell apoptosis through Bcl-2 downregulation. It also demonstrated for the first time that 


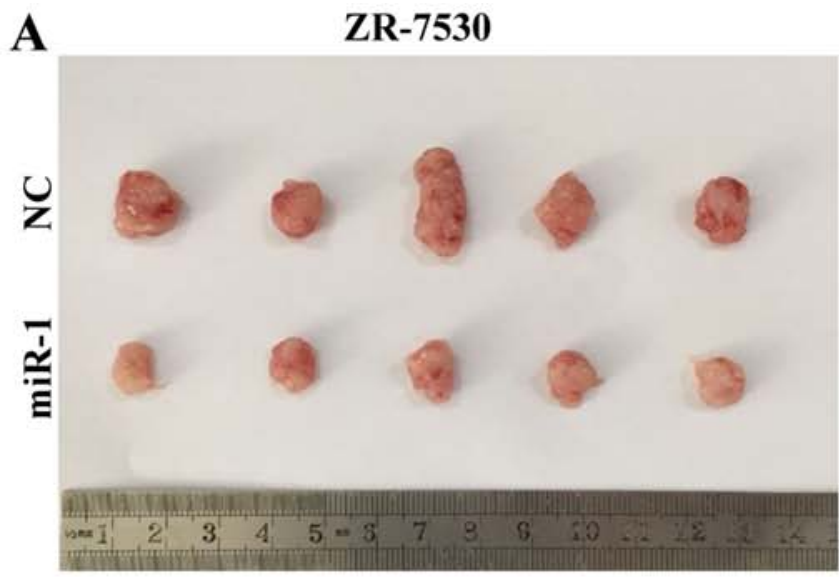

B

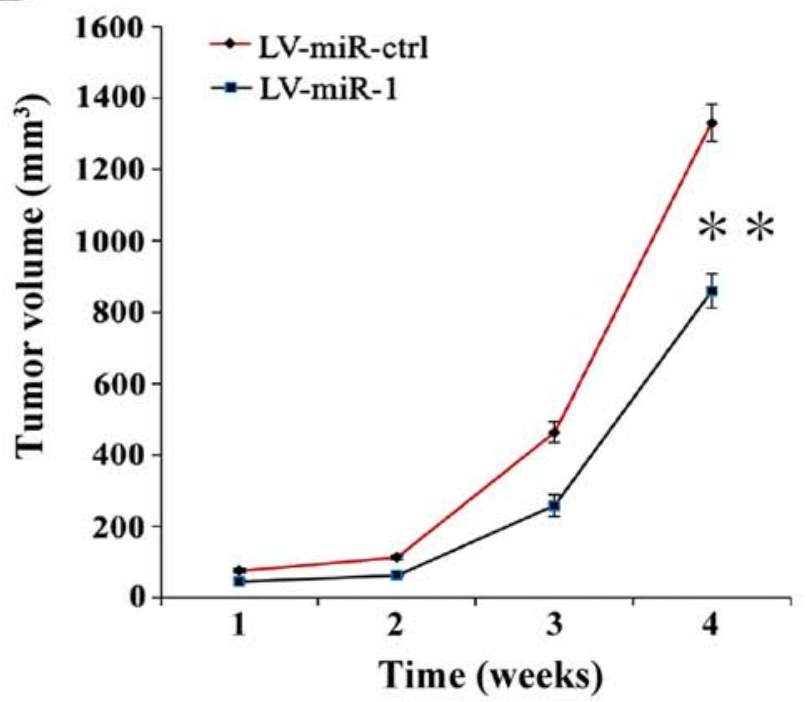

C

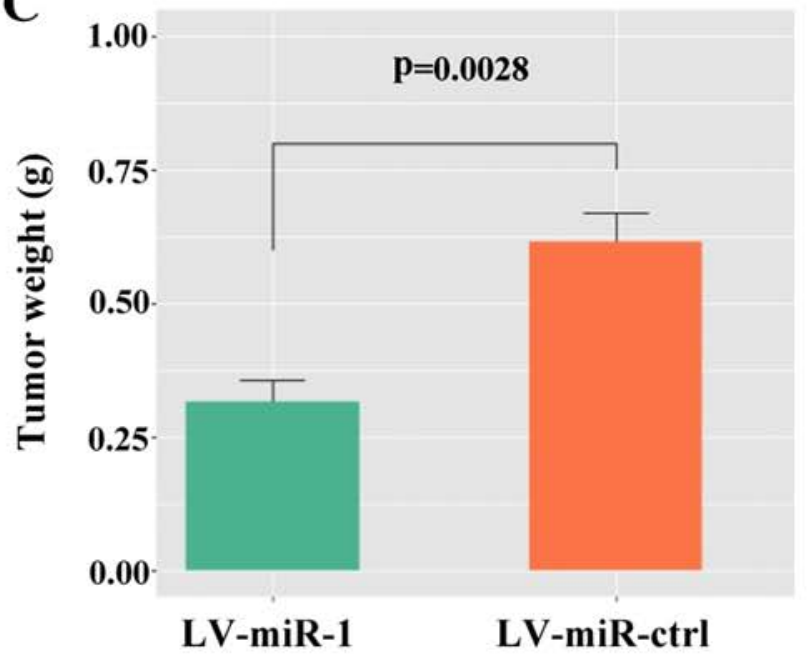

MCF-7
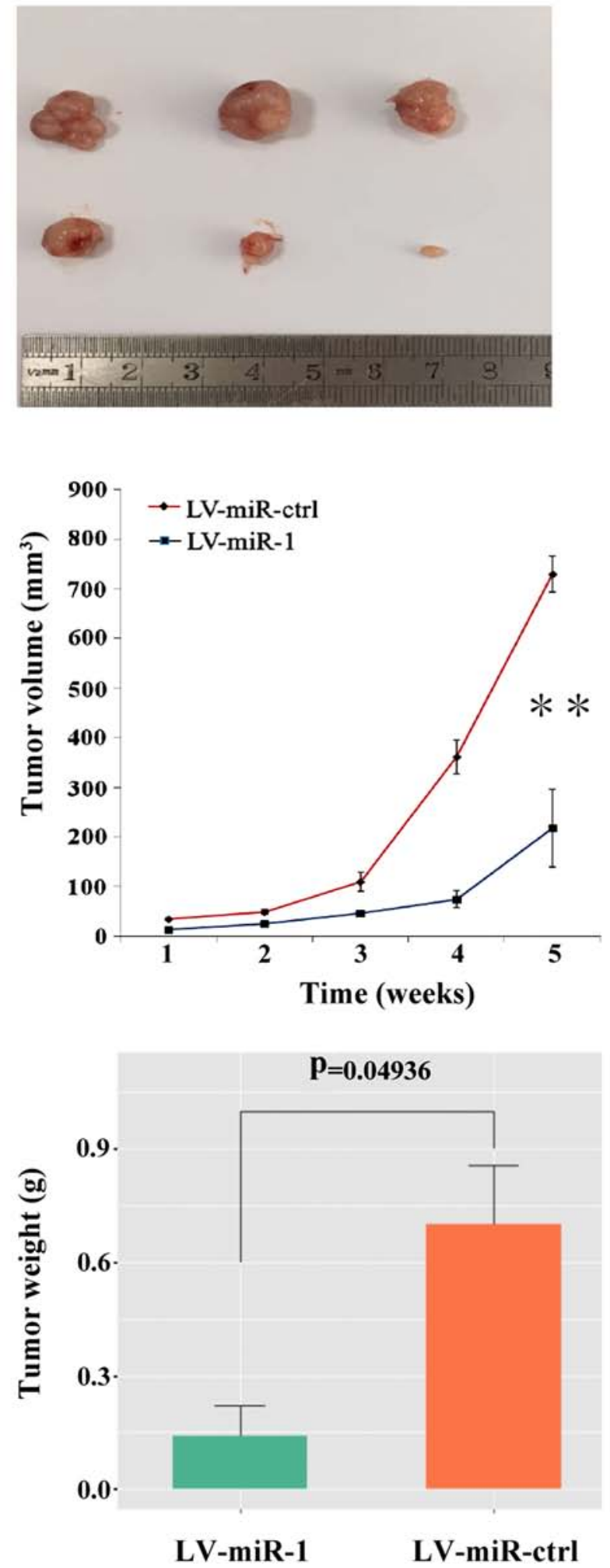

Figure 6. Upregulation of miR-1 leads to tumor suppression in vivo. (A) Tumors were resected 4 weeks or 5 weeks after initial cell inoculation in the ZR-7530 group and the MCF-7 group, respectively ( $\mathrm{n}=5$ for the ZR-7530 group; $\mathrm{n}=3$ for the MCF-7 group). (B) Upregulation of miR-1 decreased the tumor volume compared with the control. (C) Upregulation of miR-1 decreased the tumor weight compared with the control. ${ }^{* *} \mathrm{P}<0.01$. miR, microRNA; NC, normal control; ctrl, control; LV, lentiviral; ctrl, control.

miR-1-overexpressing BC cells are more sensitive to paclitaxel and DDP.

The present study found that miR-1 was expressed at low levels in BC tissues. Therefore, it was hypothesized that
miR-1 may be a tumor suppressor gene in BC. In vitro experiments indicated that transfection of MCF-7 and ZR-7530 cells with miR-1 can inhibit cell growth. Flow cytometry analysis revealed that overexpression of miR-1 can promote cell 

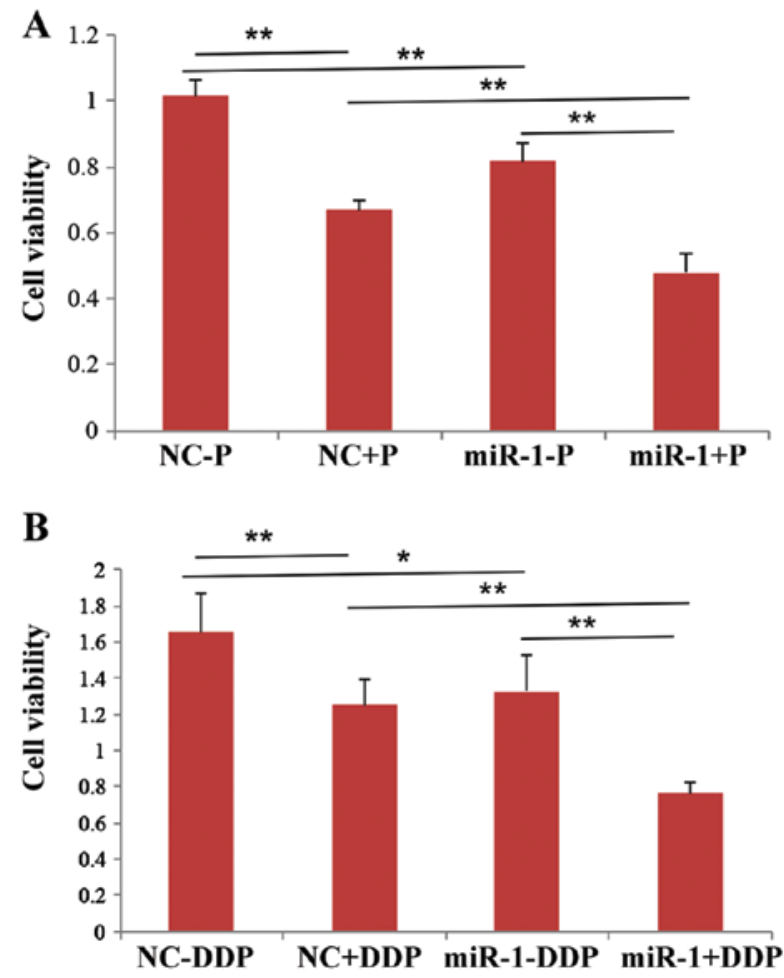

C

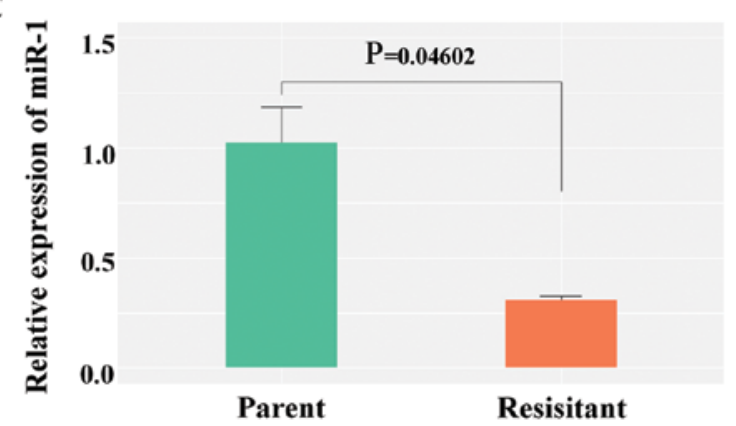

Figure 7. miR-1 enhances paclitaxel and cisplatin sensitivities in breast cancer. (A) Paclitaxel (P) sensitivity was increased in miR-1-overexpressing MCF-7 cells (miR-1+P), and cell viability was decreased compared with the control group $(\mathrm{NC}+\mathrm{P})$. (B) Cisplatin (DDP) sensitivity was increased in miR-1-overexpressing MCF-7 cells (miR-1+P), and cell viability was decreased compared with the control group $(\mathrm{NC}+\mathrm{P})$. (C) miR-1 was downregulated in cisplatin-resistant $\mathrm{BC}$ cells $(\mathrm{P}=0.046)(\mathrm{n}=3),{ }^{*} \mathrm{P}<0.05$ and ${ }^{* *} \mathrm{P}<0.01$. miR, microRNA; BC, breast cancer.

apoptosis. These results were consistent with those of a previous study, which reported that a high level of miR-1 can inhibit the growth of hepatocellular carcinoma cells by promoting apoptosis (18). Western blotting data also showed that proteins that promote apoptosis such as Bax, cleaved PARP and cleaved caspase-3, were increased in miR-1-overexpressing cells. In contrast, p-AKT, Bip and Mcl-1, which are important for proliferation, were decreased in the miR-1 overexpression group. To evaluate the role of miR-1 in the regulation of the cell cycle or DNA damage in BC cells, the expression of related genes was analyzed, but no significant difference was observed between BC cells in which miR-1 was stably expressed and negative control cells. Only p21, which mediates the $\mathrm{p} 53$ tumor suppressor gene, was upregulated in LV-miR-1 cells. Notably, in agreement with the findings of the present study, p21 has also been shown to be regulated by miR-1 in rhabdomyosarcoma (23). Further investigation revealed that overexpression of miR-1 can inhibit cell migration and invasion. In addition, the EMT-related protein ZEB1 was downregulated in miR-1-overexpressing cells. These data implied that miR-1 may act as a tumor suppressor gene in BC by promoting apoptosis and inhibiting EMT.

The potential target genes of miR-1 were investigated next. $\mathrm{Bcl}-2$ belongs to a group of related proteins that play key roles in apoptosis, or programmed cell death $(20,24)$. The over-expression of Bcl-2 protein has been identified in numerous types of tumors, including BC. Western blot analysis revealed that miR-1 can bind to $\mathrm{Bcl}-2$ and decrease $\mathrm{Bcl}-2$ protein levels in $\mathrm{BC}$ cells. A luciferase assay also provided evidence that miR-1 can directly regulate Bcl-2 mRNA expression by targeting the Bcl-2 3'-UTR. Consistent with the results of the present study, Tang et al (25) reported that miR-1 is closely related to ischemia/reperfusion injury in a rat model and that the level of miR-1 is inversely correlated with $\mathrm{Bcl}-2$ expression in cardiomyocytes in a I/R rat model.

Finally, the function of miR-1 in drug resistance was investigated. The over-expression of $\mathrm{Bcl}-2$ has been shown to regulate the development of drug resistance in $\mathrm{BC}(26,27)$. Paclitaxel and DDP are among the well-known chemotherapy drugs used to treat numerous types of tumors, including BC (28). The authors' previous study demonstrated that neoadjuvant chemotherapy consisting of a paclitaxel and DDP combination was highly effective for BC patients (29). However, drug resistance is a key obstacle to the success of chemotherapy (30). It was therefore hypothesized that miR-1 may sensitize BC cells to anticancer drugs by targeting $\mathrm{Bcl}-2$, which protects $\mathrm{BC}$ cells from apoptosis. Indeed, the data from the present study showed that paclitaxeland DDP-induced apoptosis was increased in BC cells that overexpressed miR-1. Similar the current study, Hua et al (31) reported that miR-1 overexpression improved DDP sensitivity by inhibiting ATG3-mediated autophagy in non-small cell lung cancer cells. Thus, miR-1 may have a role in the treatment of $\mathrm{BC}$ patients who are administered paclitaxel and DDP, but the specific mechanism requires further investigation in the future.

The present study illustrated that miR-1 is expressed at low levels in BC samples and can regulate cell proliferation and migration by downregulating Bcl-2. The data also showed that miR-1 can increase the sensitivity of BC cells to paclitaxel and DDP. In conclusion, miR-1 is a candidate tumor suppressor in human BC and increasing the expression of miR-1 may be a potential treatment strategy for $\mathrm{BC}$.

\section{Acknowledgements}

Not applicable.

\section{Funding}

The present study was supported by the Multidisciplinary Cross Research Foundation of Shanghai Jiaotong University (grant nos. ZH2018QNA42 and YG2017QN49) and the Shanghai Natural Science Foundation (grant no. 19ZR1431100), the Shanghai Municipal Commission of Health and Family Planning (grant no. 201640006), the Clinical Research Plan of SHDC (grant no. 12016231 and 16CR3065B), and the Incubating Program for Clinical Research and Innovation of Renji Hospital (grant no. PYMDT-002). 


\section{Availability of data and materials}

All datasets used and/or analyzed during the current study are available from the corresponding author on reasonable request.

\section{Authors' contributions}

LZ and JL provided the concept and designed the designed the experiments of the study. JP and CY performed the experiments. ZW and WY performed the statistical and bioinformatics analysis. YW and YL collected the clinical samples and contributed to the interpretation of the data. JP wrote and YW helped revised the manuscript. All authors read and approved the final manuscript.

\section{Ethics approval and consent to participate}

The Ethics Committee of Renji Hospital affiliated with Shanghai Jiaotong University of Medicine approved the protocol and written informed consent was provided by the included patients and healthy controls.

\section{Patient consent for publication}

All BC patients provided written informed consent for the use of their specimens in this study.

\section{Competing interests}

The authors declare that they have no competing interests.

\section{References}

1. Siegel RL, Miller KD and Jemal A: Cancer statistics. CA Cancer J Clin 68: 7-30, 2018.

2. Minemura H, Takagi K, Miki Y, Shibahara Y, Nakagawa S, Ebata A, Watanabe M, Ishida T, Sasano H and Suzuki T: Abnormal expression of miR-1 in breast carcinoma as a potent prognostic factor. Cancer Sci 106: 1642-1650, 2015.

3. Gerratana L, Fanotto V, Bonotto M, Bolzonello S, Minisini AM, Fasola G and Puglisi F: Pattern of metastasis and outcome in patients with breast cancer. Clin Exp Metastasis 32: 125-133, 2015

4. Higgins MJ and Baselga J: Targeted therapies for breast cancer. J Clin Invest 121: 3797-3803, 2011.

5. Ali S and Coombes RC: Endocrine-responsive breast cancer and strategies for combating resistance. Nat Rev Cancer 2: 101-112, 2002.

6. Piao HL and Ma L: Non-coding RNAs as regulators of mammary development and breast cancer. J Mammary Gland Biol Neoplasia 17: 33-42, 2012.

7. Filipowicz W, Bhattacharyya SN and Sonenberg N: Mechanisms of post-transcriptional regulation by microRNAs: Are the answers in sight? Nat Rev Genet 9: 102-114, 2008.

8. Lu J, Getz G, Miska EA, Alvarez-Saavedra E, Lamb J, Peck D, Sweet-Cordero A, Ebert BL, Mak RH, Ferrando AA, et al: MicroRNA expression profiles classify human cancers. Nature 435: 834-838, 2005.

9. Tavazoie SF, Alarcon C, Oskarsson T, Padua D, Wang Q, Bos PD, Gerald WL and Massague J: Endogenous human microRNAs that suppress breast cancer metastasis. Nature 451: $147-152,2008$

10. Nohata N,Hanazawa T, Enokida H and Seki N: microRNA-1/133a and microRNA-206/133b clusters: Dysregulation and functional roles in human cancers. Oncotarget 3: 9-21, 2012.

11. Hudson RS, Yi M, Esposito D, Watkins SK, Hurwitz AA, Yfantis HG, Lee DH, Borin JF, Naslund MJ, Alexander RB, et al: MicroRNA-1 is a candidate tumor suppressor and prognostic marker in human prostate cancer. Nucleic Acids Res 40: 3689-3703, 2012.
12. Liu C, Zhang S, Wang Q and Zhang X: Tumor suppressor miR-1 inhibits tumor growth and metastasis by simultaneously targeting multiple genes. Oncotarget 8: 42043-42060, 2017.

13. Liu T, Hu K, Zhao Z, Chen G, Ou X, Zhang H, Zhang X, Wei X, Wang D, Cui M and Liu C: MicroRNA down-regulates proliferation and migration of breast cancer stem cells by inhibiting the Wnt/ß-catenin pathway. Oncotarget 6: 41638-41649, 2015.

14. Livak KJ and Schmittgen TD: Analysis of relative gene expression data using real-time quantitative PCR and the 2(-Delta Delta C(T)) method. Methods 25: 402-408, 2001.

15. Lu J, Zhao FP, Peng ZL, Zhang MM, Lin SX, Liang BJ, Zhang B, Liu X, Wang L, Li G, et al: EZH2 promotes angiogenesis through inhibition of miR-1/Endothelin-1 axis in nasopharyngeal carcinoma. Oncotarget 5: 11319-11332, 2014.

16. Sheng JY, Shi BL and Chen HF: Establishment and appraisal of DDP resistant variant of triple negative breast cancer cell line MDA-MB-231. Cancer Res Prev Treat 43: 175-180, 2016.

17. Cancer Genome Atlas Network: Comprehensive molecular portraits of human breast tumours. Nature 490: 61-70, 2012.

18. Datta J, Kutay H, Nasser MW, Nuovo GJ, Wang B, Majumder S, Liu CG, Volinia S, Croce CM, Schmittgen TD, et al: Methylation mediated silencing of MicroRNA-1 gene and its role in hepatocellular carcinogenesis. Cancer Res 68: 5049-5058, 2008.

19. Chang YS, Chen WY, Yin JJ, Sheppard-Tillman H, Huang J and Liu YN: EGF receptor promotes prostate cancer bone metastasis by downregulating miR-1 and activating TWIST1. Cancer Res 75: 3077-3086, 2015.

20. Adams JM and Cory S: The Bcl-2 apoptotic switch in cancer development and therapy. Oncogene 26: 1324-1337, 2007.

21. Nasser MW, Datta J, Nuovo G, Kutay H, Motiwala T, Majumder S, Wang B, Suster S, Jacob ST and Ghoshal K: Down-regulation of micro-RNA-1 (miR-1) in lung cancer. Suppression of tumorigenic property of lung cancer cells and their sensitization to doxorubicin-induced apoptosis by miR-1. J Biol Chem 283: 33394-33405, 2008.

22. Yoshino H, Chiyomaru T, Enokida H, Kawakami K, Tatarano S, Nishiyama K, Nohata $N$, Seki $N$ and Nakagawa M: The tumour-suppressive function of miR-1 and miR-133a targeting TAGLN2 in bladder cancer. Br J Cancer 104: 808-818, 2011.

23. Yan D, Dong Xda E, Chen X, Wang L, Lu C, Wang J, Qu J and Tu L: MicroRNA-1/206 targets c-Met and inhibits rhabdomyosarcoma development. J Biol Chem 284: 29596-29604, 2009.

24. Cory S, Huang DC and Adams JM: The Bcl-2 family: Roles in cell survival and oncogenesis. Oncogene 22: 8590-8607, 2003.

25. Tang Y, Zheng J, Sun Y, Wu Z, Liu Z and Huang G: MicroRNA-1 regulates cardiomyocyte apoptosis by targeting Bcl-2. Int Heart J 50: 377-387, 2009.

26. Davis JM, Navolanic PM, Weinstein-Oppenheimer CR, Steelman LS, Hu W, Konopleva M, Blagosklonny MV and McCubrey JA: Raf-1 and Bcl-2 induce distinct and common pathways that contribute to breast cancer drug resistance. Clin Cancer Res 9: 1161-1170, 2003.

27. Zhou M, Liu Z, Zhao Y, Ding Y, Liu H, Xi Y, Xiong W, Li G, Lu J, Fodstad O, et al: MicroRNA-125b confers the resistance of breast cancer cells to paclitaxel through suppression of pro-apoptotic Bcl-2 antagonist killer 1 (Bak1) expression. J Biol Chem 285: 21496-21507, 2010.

28. Duan Z, Lamendola DE, Duan Y, Yusuf RZ and Seiden MV: Description of paclitaxel resistance-associated genes in ovarian and breast cancer cell lines. Cancer Chemother Pharmacol 55: $277-285,2005$

29. Zhou L, Xu S, Yin W, Lin Y, Du Y, Jiang Y, Wang Y, Zhang J, $\mathrm{Wu} \mathrm{Z}$ and Lu J: Weekly paclitaxel and cisplatin as neoadjuvant chemotherapy with locally advanced breast cancer: A prospective, single arm, phase II study. Oncotarget 8: 79305-79314, 2017.

30. Siddik ZH: Cisplatin: Mode of cytotoxic action and molecular basis of resistance. Oncogene 22: 7265-7279, 2003.

31. Hua L, Zhu G and Wei J: MicroRNA-1 overexpression increases chemosensitivity of non-small cell lung cancer cells by inhibiting autophagy related 3-mediated autophagy. Cell Biol Int 42: $1240-1249,2018$

This work is licensed under a Creative Commons Attribution-NonCommercial-NoDerivatives 4.0 International (CC BY-NC-ND 4.0) License. 